\title{
Micromechanical interpretation of thermo-plastic behaviour of clays
}

\author{
Angela Casarella ${ }^{1, *}$, Alessandro Tarantino ${ }^{2}$ and Alice Di Donna ${ }^{1}$ \\ ${ }^{1}$ Univ. Grenoble Alpes, CNRS, Grenoble INP, 3SR, 38000, Grenoble (France) \\ ${ }^{2}$ Department of Civil and Environmental Engineering, University of Strathclyde (Scotland, UK)
}

\begin{abstract}
The effect of temperature on mechanical behaviour of clay-based geomaterials is relevant in a number of geotechnical applications (e.g. low enthalpy geothermal systems and energy geostructures, nuclear waste disposal, and heating in rapid shear deformation). Mechanical response of (saturated) clays upon heating is not always intuitive as volume changes may occur due to both thermal expansion of clay constituents and temperature-induced changes of clay microstructure. This paper first revisits the macroscopic thermally-induced mechanical behaviour of saturated clays available in the literature via an advanced thermoelastoplastic constitutive model and then elucidates the dependence on clay mineralogy of the two key parameters of the model (mechanical hardening and thermal softening respectively) by inspecting differences in clay inter-particle electro-chemical forces occurring in kaolinitic, illitic, and smectitic clays. The micromechanically-based interpretation of constitutive parameters can serve as a guidance for soil parameter selection in the design of energy geostructures.
\end{abstract}

\section{Introduction}

The effect of temperature on mechanical behaviour of geomaterials is a relevant problem of growing concern in geoenvironmental engineering. During the last decades, the response of soils to the combined effects of stress and temperature has been studied in depth. Nonetheless, most investigations have been carried out within the context of nuclear waste geological disposal $[1,2]$ focusing on the study of high-swelling clays subjected to high stress and temperature. The effect of temperature changes has not been extensively investigated in non-swelling or moderately active clays, which are of interest in a number of applications including shallow geothermal plants [3], energy geostructures [4], and shear heating in rapid shear movements [5].

The thermal behaviour of granular materials is governed by the thermal expansion of the grains. When a sandy soil is heated under drained conditions, its volume increases as both grains and water dilate thermoelastically (proportionally to their thermal expansion coefficients). Due to drained conditions that establish coarse-grained materials, soil water thermal expansion does not contribute to the volume variation of the material itself [4].

Volume changes in (saturated) clays occur due to both thermal expansion of clay mineral and soil water and temperature-induced changes of clay microstructure. The interaction between these two mechanisms is complex and, as a result, mechanical response of clays upon heating is not always intuitive. This includes the volumetric 'collapse' observed in normally consolidated clays upon heating. As a result, a detailed characterisation of the coupled thermo-mechanical behaviour of clays subjected to varying temperature turns out to be fundamental at the design stage.

This paper presents an insight into the experimental evidence available in the literature concerning the macroscopic thermomechanical behaviour of clays. The Advanced Constitutive Model for Environmental Geomechanics with Temperature effect, ACMEG-T [7], developed at EPFL (Switzerland), is deployed to interpret these macroscopic observations. The two key parameters of the constitutive model (mechanical hardening and thermal softening respectively) are interpreted in the light of the different electro-chemical forces assumed to control clay particle interactions in clays of different mineralogy (kaolinite, illite, and smectite).

\section{Thermomechanical response of saturated clays}

For the case of (saturated) clays, the mechanical response to thermal loading depends on loading history, being thermo-elasto-plastic for Normally Consolidated (NC) clays and thermo-elastic for highly Over-Consolidated (OC) clays (Figure 1) [8-12]. The material irreversibly and non-linearly undergoes contraction upon heating in $\mathrm{NC}$ conditions, while OC materials experience a reversible volume expansion during heating. An intermediate case is represented by slightly OC clays: the material shows initial dilation and subsequent contraction upon heating, followed by contraction during cooling.

\footnotetext{
* Corresponding author: angela.casarella@3sr-grenoble.fr
} 
This macroscopic response of clayey soils to temperature cannot be explained solely in terms of thermal expansion of the solid and pore fluid phases, as is the case of granular materials. Thermal dilations of water and clay minerals are positive (Table 1, [13]) and volumetric response upon heating should be characterised by a volumetric (elastic) expansion if controlled only by thermal dilations of individual phases. However, NC clays undergo volumetric contraction when subjected to an increase in temperature and this volume change is not recovered during subsequent cooling.

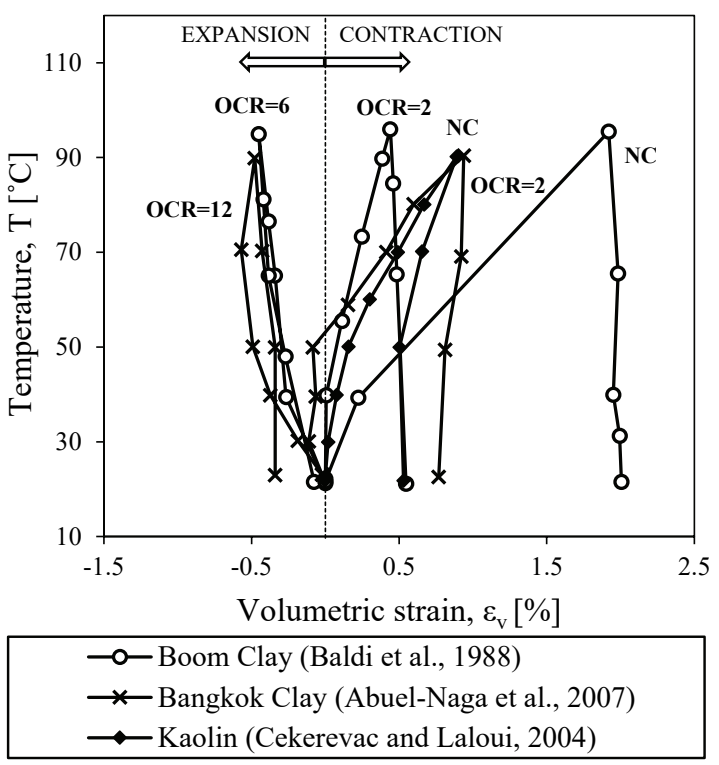

Fig. 1. Thermal volumetric behaviour of saturated clays.

Temperature therefore appears to affect the electrochemical interactions between clay particles giving rise to a more complex response of the clay-water-electrolyte system. According to [14], the clay particle surface is negatively charged and the particle edge is positively charged when the clay is mixed with 'ordinary' acidic water. Under these conditions, clay microstructure occurs as a house of cards where particles arrange themselves in face-to-face (non-contact) or edge-to-face (contact) configurations (Figure 2). Plastic volumetric deformation occurring upon mechanical loading has been associated with disengagement of edge-to-face contact with particles moving from edge-to-face to face-to-face [14]. For the case of thermally-induced plastic volumetric collapse observed in NC clays, it can therefore be tentatively assumed that an increase in temperature encourages the weakening of the net attractive force at the edge-to-face contact promoting disengagement with consequent plastic deformation [15]. Accordingly, thermally-induced plastic deformation should depend on electro-chemical forces generated between clay-particles, which depend in turn on clay mineralogy. This micro-macro interaction is further explored in the next sections.
Table 1. Volumetric thermal expansion coefficients of soil minerals and water [13].

\begin{tabular}{|c|c|}
\hline Material & $\begin{array}{c}\text { Volumetric thermal } \\
\text { expansion coefficient, } \\
\boldsymbol{\beta}_{\boldsymbol{s}}\left[\mathbf{1 0}^{-5}{ }^{\circ} \mathbf{C}^{-1}\right]\end{array}$ \\
\hline Kaolinite & 2.90 \\
\hline Illite & 2.50 \\
\hline Chlorite & 3.12 \\
\hline Water $\left(\boldsymbol{\beta}_{\boldsymbol{w}}\right)$ & $13.9+0.61 T^{*}$ \\
\hline
\end{tabular}

${ }^{*} T$ being the temperature in ${ }^{\circ} \mathrm{C}$, considering constant pressure

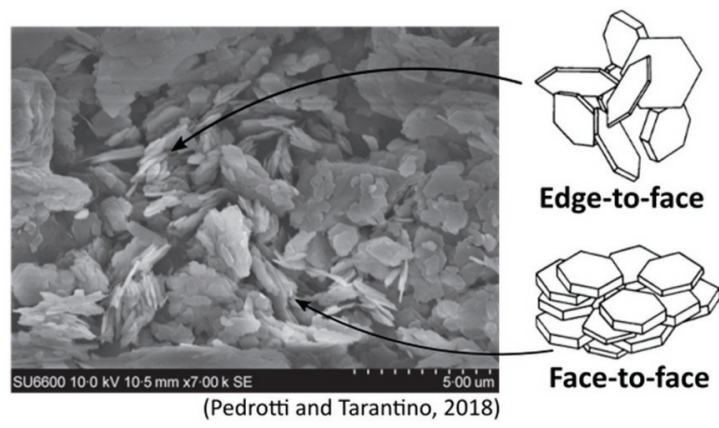

Fig. 2. SEM image on a Speswhite kaolin clay sample consolidated at $70 \mathrm{kPa}$ [14] from which kaolin clay particles can be identified.

\section{Constitutive model}

Modelling the complex non-linear and irreversible behaviour of clay, when subjected to combined thermal and mechanical loading, requires advanced constitutive models. During the last thirty years, several elastoplastic models have been developed to take into account the effects of temperature variations on the behaviour of clayey soils [16 - 19]. A Cam-Clay-based constitutive model was formulated at EPFL in Lausanne to unify the different peculiar aspects characterising the thermomechanical response of fine-grained soils: the Advanced Constitutive Model for Environmental Geomechanics, with Temperature effects (ACMEG-T) [7].

The model is based on the thermo-elastoplasticity theory and the critical state theory [20]. As the Original Cam-Clay model suffers from some inconsistencies in the prediction of the behaviour of normally consolidated soils, an isotropic yielding mechanism was added to the Original Cam-Clay deviatoric yielding mechanism. According to the theory of multi-mechanism plasticity [21], two thermo-plastic mechanisms are considered: the isotropic mechanism, $f_{i s o}$, and the deviatoric mechanism $f_{\text {dev }}$. This means that there are two different dissipative processes described through two evolution laws, activated by two yield functions, through two dissipative potentials and through two plastic multipliers [22]. The two yield functions define a closed domain in the isotropic effective stress - deviatoric stress - temperature space inside which the behaviour of the material is reversible (Figure 3).

As our purpose is to calibrate temperature-dependent constitutive parameters driving the volumetric thermal 
response, we will focus on the isotropic yield function with respect to temperature (horizontal plane in Figure 3).

\subsection{Thermo-elastic strain}

According to [7], the total deformation is composed of volumetric and deviatoric parts. In the elastic nonisothermal domain, the volumetric deformation is represented by the superposition of a reversible thermal induced strain and a mechanical elastic strain (under isothermal conditions):

$$
\varepsilon_{v}^{T e}=\beta_{s}\left(T-T_{0}\right)+\left(p^{\prime}-p^{\prime}{ }^{\prime}\right) / K
$$

where $\varepsilon_{v}{ }^{T e}[-]$ is the volumetric thermo-elastic strain, $\beta_{s}$ $\left[{ }^{\circ} \mathrm{C}^{-1}\right]$ is the volumetric thermal dilation coefficient, (T $\left.T_{0}\right)\left[{ }^{\circ} \mathrm{C}\right]$ is the temperature variation, $\left(p^{\prime}-p^{\prime}{ }^{\prime}\right)[\mathrm{kPa}]$ is the mean effective stress variation (assuming negative stresses when a compression occurs) and $K[\mathrm{kPa}]$ the bulk elastic modulus.

\subsection{Isotropic Thermoplastic Mechanism}

The development of thermo-plastic strain starts when the stress point reaches the yield limit. The yield limit of the isotropic thermoplastic mechanism is expressed by:

$$
f_{\text {iso }}=p^{\prime}-p^{\prime}{ }_{c}=0
$$

where $p_{c}{ }_{c}[\mathrm{kPa}]$ is the preconsolidation pressure at given temperature $T$, which evolves with the generated volumetric plastic strain $\varepsilon_{v}^{p}[-]$ :

$$
p_{c}^{\prime}(T)=p^{\prime}{ }_{c 0} \exp \left(\beta \varepsilon_{v}^{p}\right)
$$

with $p^{\prime}{ }_{c 0}[\mathrm{kPa}]$ being the initial preconsolidation pressure at current temperature $T$ and $\beta$ [-] being the plastic rigidity index, i.e. the slope of the linear function $\left(\varepsilon_{v}^{p}-\log p^{\prime}\right)$.

Several results from the literature show a decrease in the preconsolidation pressure with increasing temperature. Therefore, the elastic domain under isotropic loading is reduced as temperature increases, which is representative of thermal-softening. The thermal effect on the yield limit is taken into account by considering [23]:

$$
p_{c 0}^{\prime}(T)=p^{\prime}{ }_{c 0, T 0}\left[1-\gamma_{T} \log \left(T / T_{0}\right)\right]
$$

where $p_{c 0, T 0}^{\prime}[\mathrm{kPa}]$ is the initial preconsolidation pressure at temperature $T_{0}$ and $\gamma_{T}[-]$ is a model parameter.

Finally, the expression of the isotropic thermoplastic yield limit in (2) can be re-written as follows:

$$
f_{\text {iso }}=p^{\prime}-p^{\prime}{ }_{c 0, T 0} \exp \left(\beta \varepsilon_{v}{ }^{p}\right)\left[1-\gamma_{T} \log \left(T / T_{0}\right)\right]=0
$$

Equation (7) depends on two model parameters: $\beta$, expressing the evolution of mechanical hardening and $\gamma_{T}$ controlling the evolution of thermal softening. The thermal response is actually a combination of these two mechanisms: mechanical hardening and thermal softening [19].

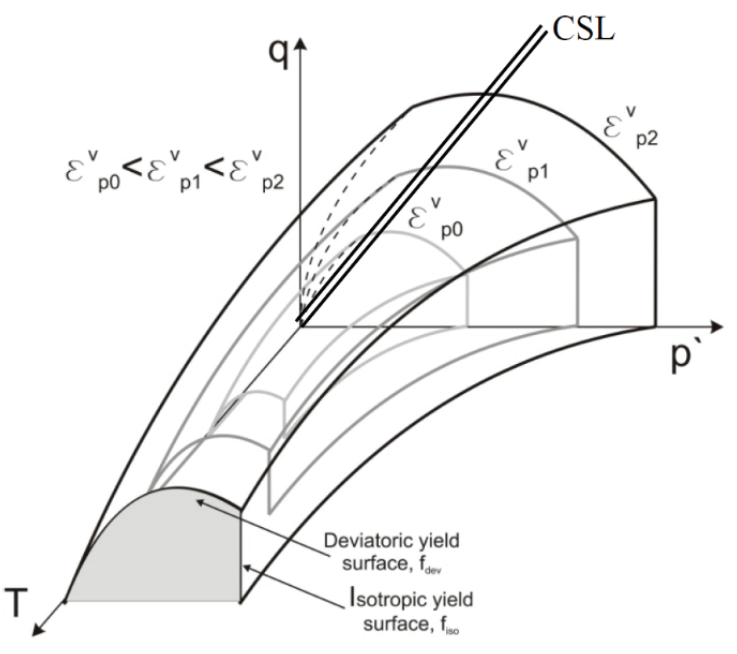

Fig. 3. Yield locus of the ACMEG-T model [4].

This model has been validated on several THM paths but its formulation depends on a number of parameters, which are not easy to identify other than by curve fitting. The challenge addressed in this paper is to provide a micromechanical interpretation to the temperature-related constitutive parameter $\gamma_{T}$ and $\beta$ (Figure 4).

In the mean effective stress-temperature plane shown in Figure 4 the initial isotropic yield function defines an elastic domain (grey space). The value $p^{\prime}{ }_{c 0}$ represents the isotropic preconsolidation pressure at the initial stage. Points A, B and C exemplify three different initial states of the material before applying a drained thermal load at constant mean effective stress. Both points $\mathrm{A}$ and $\mathrm{C}$ have a current mechanical stress lower than $p_{c 0}^{\prime}$, thus they are overconsolidated $(\mathrm{OC})$ and their thermal stress path starts in the elastic domain. Point B lies on the yielding locus and represents a normally consolidated material.

Point A represents a highly overconsolidated stress state. This means that when drained heating occurs, the stress state moves from A to A' within the elastic domain without crossing the yield surface. As shown on the $\left(T, \varepsilon_{v}\right)$ plane in Figure 4, the material elastically dilates upon heating.

Starting from point $B$, a positive temperature changes induce thermoplastic strain from B to B', which results in the contraction of the material.

The temperature-stress path of point $\mathrm{C}$ starts in the elastic domain but encounters in C', the isotropic yield surface. The material therefore responds elastoplastically, dilating elastically until it reaches C', and then starting contracting when the yield surface is dragged from C' 'to C'.

Mechanical loading from B to B" at constant temperature induces plastic deformation (mechanical strain hardening). 


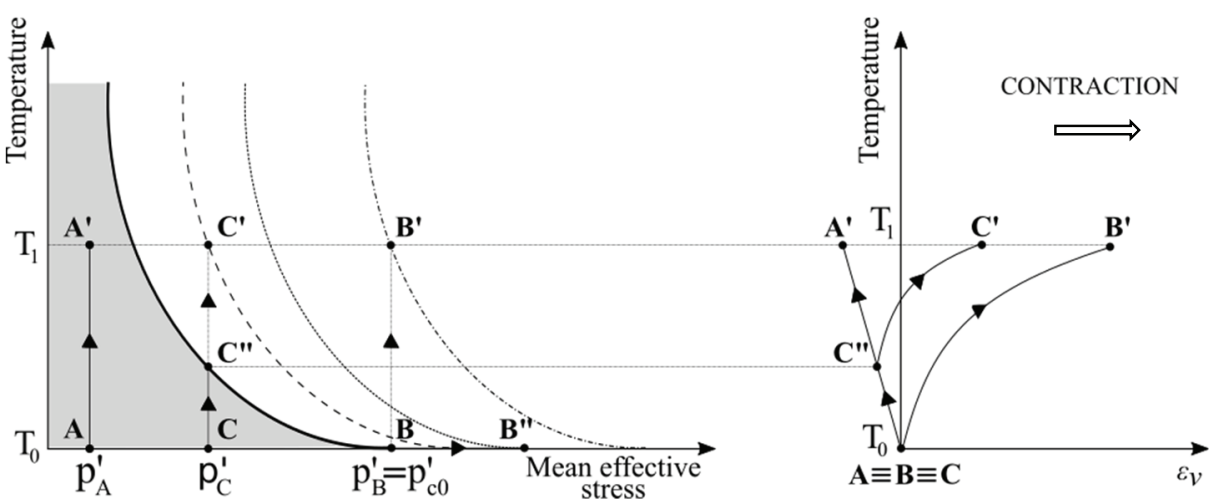

Fig. 4. Yield locus of the ACMEG-T model on $\left(T, p^{\prime}\right)$ plane and effects recorded on $\left(T, \varepsilon_{v}\right)$.

\subsection{Calibration of parameters $\beta$ and $\gamma_{T}$ on experimental results}

The ACMEG-T model was used to simulate experimental results on five different types of normally consolidated (NC) clays [8 - 12]. According to (1) and (7), the key model parameters to be determined to characterise the thermo-plastic response are $\gamma_{T}, \beta$ and $\beta_{s}$. All the considered tests are done under NC conditions, thus by definition at initial state $p^{\prime}=p_{c}^{\prime}$.

For each experimental dataset, the parameter $\gamma_{T}$ in the ACMEG-T model was calibrated by fitting the volumetric strain accumulated during thermal loading at constant isotropic effective stress. The parameter $\beta$, corresponding to the plastic rigidity index at constant temperature, was calibrated on isothermal standard mechanical tests provided by the same authors, as proposed by [23]. The volumetric thermal dilation coefficients were chosen according to characteristic values available in the literature [13].

The first example [8] consists of an isotropic drained non-isothermal test on NC remoulded Kaolin clay. The mineralogical content of the tested material was analysed by mean of X-ray diffraction [8]. It revealed the presence of kaolinite $(\sim 65 \%)$ and quartz $(\sim 35 \%)$. The heatingcooling cycle $\left(22^{\circ} \mathrm{C} \rightarrow 90^{\circ} \mathrm{C} \rightarrow 22^{\circ} \mathrm{C}\right)$ was performed at a confining pressure of $600 \mathrm{kPa}$. The NC sample contracted during heating with a non-linear volume variation, which was irreversible upon cooling.

The same calibration was performed on a remoulded NC Illite specimen tested in [9] under isotropic condition. After applying an isotropic effective stress equal to $200 \mathrm{kPa}$, the sample was subjected to a low rate temperature increase until reaching $60^{\circ} \mathrm{C}$ and subsequently to a controlled cooling down to $5^{\circ} \mathrm{C}$.

The model parameter $\gamma_{T}$ of the Boom clay was calibrated against an isotropic consolidation test at constant effective stress $\left(p^{\prime}{ }_{c}=6 \mathrm{MPa}\right)$ performed by [10] on natural Belgian Boom Clay. The tested material was a relatively soft, highly plastic, smectitic clay composed by $22 \%$ smectite, $29 \%$ kaolinite and $19 \%$ illite. Even in this case the thermal loading was applied at a very low heating rate under computer controlled zero pore pressure condition, from $20^{\circ} \mathrm{C}$ to $95^{\circ} \mathrm{C}$ and then back to $20^{\circ}$.

Natural soft Bangkok clay, obtained from 3.0 to $4.0 \mathrm{~m}$ depth, was used in the isotropic and non-isotropic experimental campaign conducted by [11]. The mineralogical composition of the material was analyzed by X-ray diffraction, revealing that this soft Bangkok clay consisted of smectite and illite, ranging from 54 to $71 \%$ with kaolinite $28-36 \%$ and mica [11]. After imposing an isotropic effective stress of $300 \mathrm{kPa}$, the specimen was subjected to drained heating and subsequent cooling $\left(22^{\circ} \mathrm{C} \rightarrow 90^{\circ} \mathrm{C} \rightarrow 22^{\circ} \mathrm{C}\right)$, showing a marked irreversible volumetric strain.

Table 2. Constitutive parameters $\beta, \beta_{s}$ and $\gamma_{T}$ evaluated for five different types of clay.

\begin{tabular}{|c|c|c|c|c|c|c|c|c|}
\hline \multirow{2}{*}{ Clay type } & \multicolumn{4}{|c|}{ Mineralogical composition } & \multirow{2}{*}{ Test } & \multirow{2}{*}{$\beta[-]$} & \multirow{2}{*}{$\beta_{s}\left[10^{-5}{ }^{\circ} \mathrm{C}^{-1}\right]$} & \multirow{2}{*}{$\gamma_{T}[-]$} \\
\hline & Kaolinite [\%] & Illite [\%] & Smectite [\%] & Others [\%] & & & & \\
\hline Kaolin [8] & 65 & $\sim 0$ & $\sim 0$ & 35 (quartz) & ISO & 21.0 & 2.9 & 0.14 \\
\hline Illite [9] & $\sim 0$ & $\sim 96$ & $\sim 0$ & $\sim 4$ & ISO & 22.2 & 2.5 & 0.17 \\
\hline Boom Clay [10] & 29 & 19 & 22 & 30 (quartz) & ISO & 18.0 & 1.8 & 0.21 \\
\hline Bangkok Clay [11] & $28-36$ & \multicolumn{2}{|c|}{$54-71$} & $1-18$ (mica) & ISO & 5.5 & 3.5 & 0.21 \\
\hline Natural Clay [12] & \multicolumn{4}{|c|}{ unknown mineralogical composition } & OED & 67.0 & 1.8 & 0.25 \\
\hline
\end{tabular}




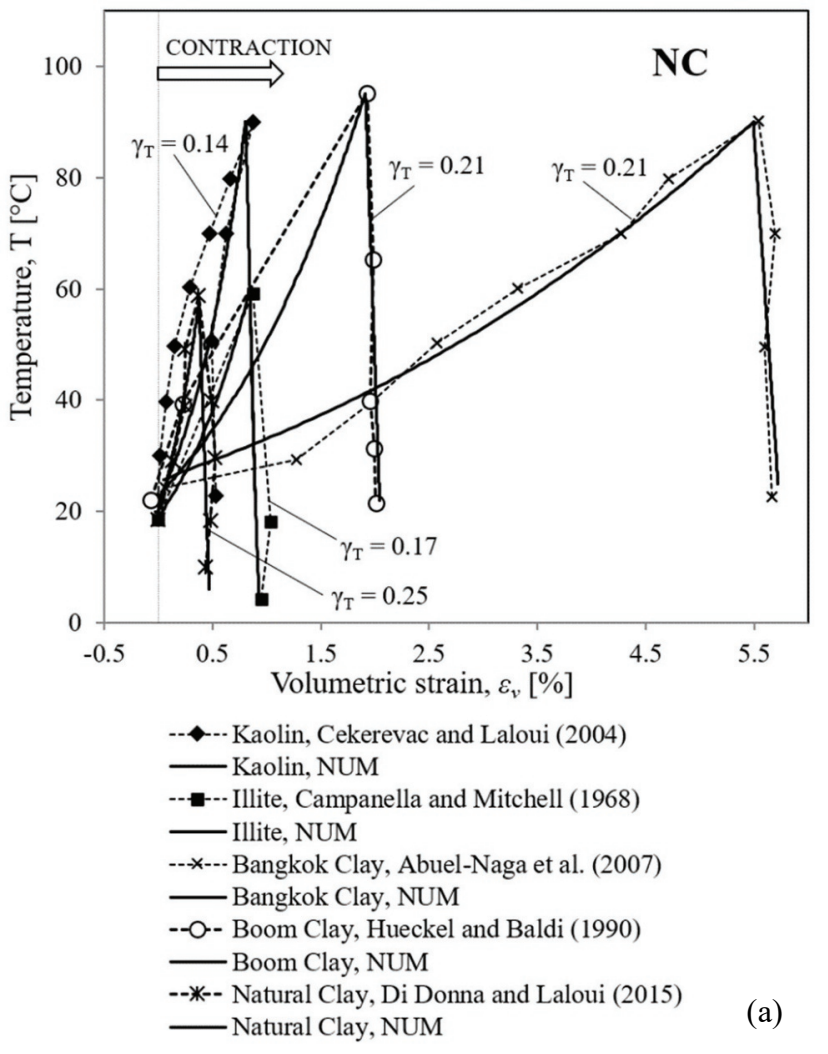

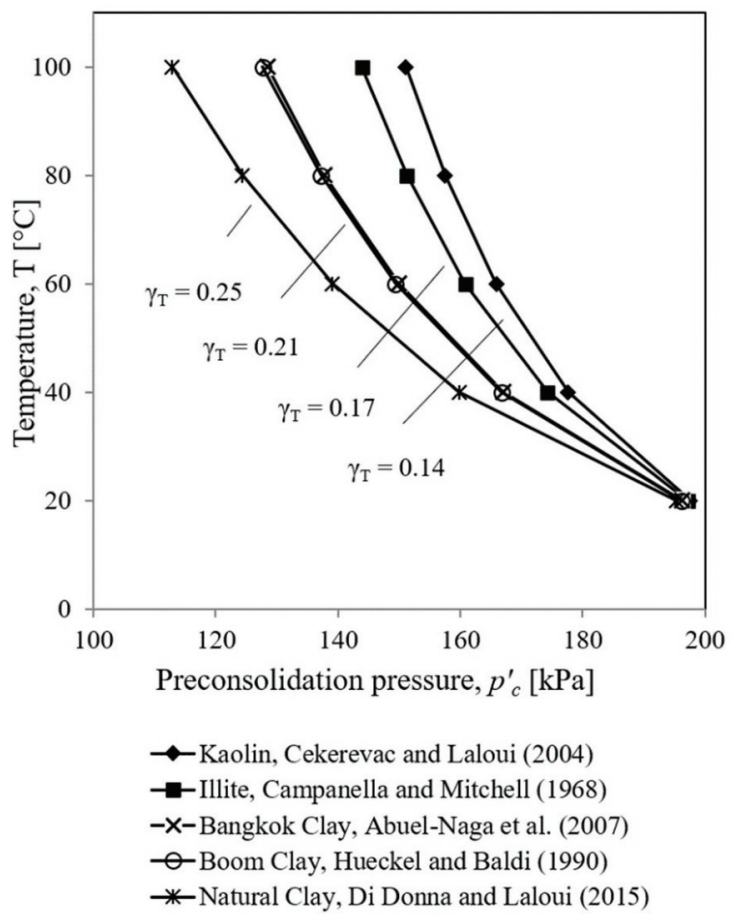

(b)

Fig. 5. (a) Calibration of the ACMEG-T parameter $\gamma_{T}$ for five different type of clay; (b) Shape of the isotropic thermomechanical yield limit for the different values of the parameter $\gamma_{T}$.

Finally, a natural Clay collected in situ near Geneva, in Switzerland was analysed by [12]. According to the material characterisation in [12], the tested clay is poorly plastic $(\mathrm{PI}<20 \%)$ but there is no specific record of the mineralogical content. In this case, the $\mathrm{NC}$ specimen underwent a thermal cyclic loading $\left(20^{\circ} \mathrm{C} \rightarrow 60^{\circ} \mathrm{C} \rightarrow\right.$ $\left.5^{\circ} \mathrm{C}\right)$ under oedometer condition $\left(\sigma^{\prime}{ }_{v}=200 \mathrm{kPa}\right)$.

The calibrated values of $\beta$ and $\gamma_{T}$ are given in Table 2 while the comparison between experimentally observed and predicted volumetric strains for the three aforementioned clays is presented in Figure 5a.

The dependency of the shape of the yield locus on the parameter $\gamma_{T}$ is shown in Figure 5b. It appears that $\gamma_{T}$ increases as the fraction of active minerals (e.g. smectite). Similarly, the plastic rigidity index $\beta$ seems to decrease with the fraction of active minerals (compressibility increases).

\section{Discussion}

The effect of active clay fraction on the parameters $\beta$ and $\gamma_{T}$ is consistent with the micromechanical model discussed in Section 2. Plastic compression at constant temperature is associated with the disengagement of edge-to-face contacts. The weaker is the edge-to-face net attractive force, the higher is the rate of loss of edge-to-face contacts and, hence, the compressibility.

According to [26], alumina, which is exposed at the edges of clay particles, is amphoteric, and it ionizes positively at low $\mathrm{pH}$ and negatively at high $\mathrm{pH}$. As a result, positive diffuse layers can develop at the edges of some clay particles in an acid environment.

The force developing at the edge-to-face contact is the sum of two opposite forces, the van der Waals attraction (activated by the attraction between the positively charged edge and the negatively charged surface) and the Coulombian repulsion between the adjacent negatively charged surfaces as shown in Fig. 6. Since van der Waals forces prevail, the resulting force is attractive. Nonetheless, the intensity of the edge-to-face 'net' attractive force is influenced by the Coulombian (doublelayer) repulsion between the negatively charged faces.

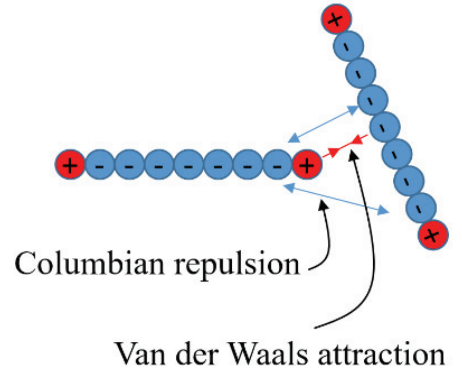

Fig. 6 Sketch of the electrochemical interaction at the edge-toface contact [15].

The existence of positive edge charges in low $\mathrm{pH}$ environment is of greatest importance in kaolinite, lesser importance in illite, and relatively unimportant in smectite 
[26]. This can be due to the smaller thickness-to-length ratio of the particle of active clay minerals.

Individual particles of non-swelling clay minerals (such as kaolinite and illite) are much thicker than smectite unit layer platelets and may consist of up to several hundred unit cell layers (see thickness $t$ and diameter $a$ in Table 3).

Table 3. Particle thickness and particle diameter of some clay minerals [29].

\begin{tabular}{|c|c|c|}
\hline Natural clay & $\begin{array}{c}\boldsymbol{a} \\
{[\boldsymbol{\mu m}]}\end{array}$ & $\begin{array}{c}\boldsymbol{t} \\
{[\boldsymbol{\mu \mathrm { m } ]}]}\end{array}$ \\
\hline Kaolinite & $0.5-4$ & $0.5-2$ \\
\hline Illite & $0.5-10$ & $0.003-0.1$ \\
\hline $\begin{array}{c}\text { Smectite } \\
\text { (single platelet) }\end{array}$ & $0.05-10$ & 0.00095 \\
\hline
\end{tabular}

Smectite clay particles are usually assumed to be a single unit layer platelets in the double layer theory. In reality, this is usually not the case, and the platelets stack into quasi-crystals [27]. For instance, when the adsorbed cation is a divalent cation, a typical quasi-crystal consists of four to seven smectite platelets interspersed by two or three molecular layers of water [28].

For clay minerals with a small thickness-to-diameter ratio such as smectite, the contribution of the termination sites at the edges is small relative to the total charge of the particles. In low $\mathrm{pH}$ environment, the positively charged surface-to-total surface area ratio is significantly lower than in illite and kaolinite. The effect of the double layer repulsion between negatively charged faces is predominant in active clay minerals and it influences the intensity of the edge-to-face 'net' attractive force. Therefore, the edge-to-face disengagement turns out to be slightly easier for active minerals thus explaining the decreasing value of $\beta$ with increasing active clay fraction.

In addition, the derivative of the repulsion force $F_{\delta}[\mathrm{N}]$ with respect to temperature $T\left[{ }^{\circ} \mathrm{C}\right]$ according to [15] can be written as:

$$
\frac{d F_{\delta}}{d T}=-\frac{\pi \cdot a^{2}}{8} \rho^{2}\left(\frac{\delta}{\sqrt{a^{2}+\delta^{2}}}-1\right) \frac{1}{\varepsilon^{2}} \frac{d \varepsilon}{d T}
$$

where $a[\mathrm{~m}]$ is the clay particle diameter, $\rho\left[\mathrm{C} \cdot \mathrm{m}^{-2}\right]$ is the uniform surface charge distribution, $\delta[\mathrm{m}]$ is the middistance between particle, and $\varepsilon\left[\mathrm{C}^{2} \cdot \mathrm{N}^{-1} \cdot \mathrm{m}^{-2}\right]$ is the static dielectric permittivity of the pore fluid. Since $d \varepsilon / d T$ is negative, the derivative $d F_{\delta} / d T$ is positive, i.e. the repulsive force increases with temperature and, hence the net edge-to-face attraction decreases with temperature. This would explain the shape of the yield locus in Fig. 4, i.e. the thermal softening. At the same time, the derivative $d F_{\delta} / d T$ is proportional to the clay particle diameter $a$, i.e. the thermal softening increases with the fraction of larger particles. The particle size $a$ has a tendency to increase going from kaolin to illite and from illite to smectite (Table 3 ). This would partially explain why the values of $\gamma_{T}$ found for kaolin are slightly lower than those for illite, which are slightly lower than those for smectite.

\section{Conclusions}

Mechanical response of (saturated) clays upon heating is not intuitive and includes the volumetric 'collapse' observed in normally consolidated clays. Numerical modelling of thermal effects in clays is relevant in many specific applications. In this paper, an advanced thermoplastic constitutive model was employed to interpret the macroscopic behaviour of saturated clays.

Some of the thermoelastic-thermoplastic evidences available in literature were reproduced with the aforementioned model. The effect of mineralogy on two key parameters of the model, namely the plastic rigidity index and the thermal softening, was explained in the light of temperature effects affecting electrochemical interactions between clay particles.

Acknowledgements: This work was funded by the ANR project GEO2 (ANR-19-CE05-0003-01). The laboratory 3SR is part of the LabEx Tec 21 (Investissement d'avenir - grant agreement n. ANR-11-LABX-0030)

\section{References}

1. E. Romero, M. Villar and A. Lloret. Thermo-HydroMechanical Behaviour of Two Heavily Overconsolidated Clays. Engineering Geology, 81, 255-268 (2005).

2. P. Braun, S. Ghabezloo, P. Delage, et al. Determination of Multiple Thermo-HydroMechanical Rock Properties in a Single Transient Experiment: Application to Shales. Rock Mech Rock Eng 52, 2023-2038 (2019).

3. K. Murphy and J. McCartney. Seasonal Response of Energy Foundations during Building Operation. Geotechnical and Geological Engineering, 33, 343356 (2015).

4. L. Laloui and A. Di Donna. Energy geostructures: innovation in underground engineering (ISTE Ltd and John Wiley \& sons Inc., 2013).

5. J. Sulem, P. Lazar, I. Vardoulakis. Thermo-PoroMechanical Properties of Clayey Gougeand Application to Rapid Fault Shearing. Int. J. Numer. Anal. Meth. Geomech., 31, 523-554 (2007).

6. A. Di Donna, M. Barla, T. Amis. Energy geostructures: analysis from research and systems installed around the world. Proceedings of $42^{\text {nd }}$ DFI Conference, (2017).

7. B. François, L. Laloui. ACMEG-TS: a constitutive model for unsaturated soils under non-isothermal conditions. Int. J. Numer. Anal. Meth. Geomech., 32, 1955-1988 (2008).

8. C. Cekerevac and L. Laloui. Experimental study of thermal effects on the mechanical behaviour of a clay. Int. J. Numer. Anal. Meth. Geomech., 28, 209228 (2004).

9. R. G. Campanella and J. K. Mitchell. Influence of temperature variations on soil behaviour. Jour. Soil Mech. and Found. Div., ASCE, 94 (1968). 
10. T. Hueckel and M. Borsetto. Thermoplasticity of Saturated Soils and Shales: Constitutive Equations. J Geotech Eng, 116, 1765-77 (1990).

11. H. Abuel-Naga, D. Bergado, and A. Bouazza. Thermally induced volume change and excess pore water pressure of soft Bangkok clay. Engineering Geology, 89, 144-154 (2007).

12. A. Di Donna, L. Laloui. Response of soil subjected to thermal cyclic loading: experimental and constitutive study. Engineering Geology, 190, 65-76 (2015).

13. D. Dixon, M. Gray, B. Lingnau, J. Graham and S. Campbell. Thermal expansion testing to determine the influence of pore water structure on water flow through dense clays. Proceedings of $46^{\text {th }}$ Canadian Geotechnical Conference, Saskatoon (1993).

14. M. Pedrotti and A. Tarantino. An experimental investigation into the micromechanics of non-active clays. Géotechnique, 68, 1-18 (2018).

15. A. Casarella, M. Pedrotti, A. Tarantino and A. Di Donna. A critical review of the effect of temperature on clay inter-particle forces and its effect on macroscopic thermal behaviour of clay. Proceedings of $16^{\text {th }}$ IACMAG, Torino (2021).

16. H. Modaressi and L. Laloui. A thermo-viscoplastic constitutive model for clays. Int J Numer Anal Meth Geomech, 21, 313-35 (1997).

17. Y.J. Cui, N. Sultan and P. Delage. $A$ thermomechanical model for clays. Can Geotech J, 37, 607-620 (2000).

18. J. Graham, N. Tanaka, T. Crilly and M. Alfaro. Modified Cam-Clay modeling of temperature effects in clays. Can Geotech J, 38, 608-621 (2001).

19. T. Hueckel and R. Pellegrini. Thermoplastic modeling of undrained failure of saturated clay due to heating. Soils Fund, 31, 1-16 (1991).

20. A. Schofield and P. Worth. Critical State Soil Mechanics (McGraw-Hill, 1968).

21. J. Mandel. Generalisation de la theorie de plasticite de W.T. Koiter. Int. J. Solids Struct, 1, 273-295 (1965).

22. L. Laloui and C. Cekerevac. Numerical simulation of the non-isothermal mechanical behaviour of soils. Comp Geotech, 35, 729-745 (2008).

23. B. François. Thermo-plasticity of fine-grained soils at various saturation states: application to nuclear waste disposal $(\mathrm{PhD}$ thesis, Ecole Polytechnique Fédéral de Lausanne, EPFL, Switzerland, 2008).

24. H. Casimir and D. Polder. The Influence of Retardation on the London-van der Waals Forces. Physical Review, 73, 360-372 (1948).

25. B. E. Novich and T. A. Ring. Colloid stability of clays using photon correlation spectroscopy. Clays and Clay Minerals, 32, 400 - 406 (1984).

26. J. Mitchell and K. Soga. Fundamentals of Soil Behavior (John Wiley \& Sons., 2005).

27. J. P. Quirk and L. A. G. Aylmore. Domains and Quasi-Crystalline Regions in Clay Systems. Journal of the Soil Science Society of America, 35, 652-654 (1971).

28. G. Sposito. The Chemistry of Soils (University Press, New York, 1989).

29. F.H. Chen. Foundations on Expansive Soils (Elsevier, New York, NY, 1975). 